\title{
Patterns of Progression and Feasibility of Re-biopsy After First-line Erlotinib for Advanced EGFR Mutation-positive Non-small-cell Lung Cancer
}

\author{
ANA LAURA ORTEGA-GRANADOS ${ }^{1}$, ÁNGEL ARTAL-CORTES ${ }^{2}$, DAVID AGUIAR-BUJANDA ${ }^{3}$ \\ JUANA ORAMAS ${ }^{4}$, JOSÉ LUIS FÍRVIDA ${ }^{5}$, JAVIER DE CASTRO ${ }^{6}$, JUANA CAMPILLO FUENTES ${ }^{7}$, \\ ROCÍO GORDO ${ }^{8}$, RAQUEL GALÁN $^{8}$ and JOSÉ TRIGO ${ }^{9}$ on behalf of the ASPET Study Investigators \\ ${ }^{1}$ Ciudad de Jaén University Hospital Complex, Jaén, Spain; \\ ${ }^{2}$ Miguel Servet University Hospital, Zaragoza, Spain; \\ ${ }^{3}$ University Hospital of Gran Canaria Doctor Negrín, Las Palmas de Gran Canaria, Spain; \\ ${ }^{4}$ University Hospital of Canarias, Santa Cruz de Tenerife, Spain; \\ ${ }^{5}$ University Hospital Complex of Orense, Orense, Spain; \\ ${ }^{6}$ La Paz University Hospital, Madrid, Spain; \\ ${ }^{7}$ Virgen de la Arrixaca Clinic University Hospital, El Palmar, Spain; \\ ${ }^{8}$ Roche Farma S.A, Madrid, Spain; \\ ${ }^{9}$ Virgen de la Victoria University Hospital, IBIMA, Campus de Teatinos, Málaga, Spain
}

\begin{abstract}
Aim: To assess the patterns of disease progression in advanced/metastatic epidermal growth factor receptor (EGFR)-mutant non-small-cell lung cancer (NSCLC) on first-line treatment with erlotinib and identify potential prognostic factors for progression-free survival (PFS). Patients and Methods: Patients with stage IIIB/IV EGFR-mutation-positive NSCLC receiving first-line erlotinib were followed-up until 24 months after the last patient was enrolled or until premature withdrawal for any cause. Results: A total of 127 evaluable patients were enrolled. The median PFS and overall survival were 8.8 and 19.1 months, respectively. Disease progression was asymptomatic in $57.6 \%$ of patients and $53.3 \%$ developed new sites of metastasis. The presence of liver metastasis was identified as an independent prognostic factor for poor PFS. Conclusion: Metastatic progression with asymptomatic disease seems to be the predominant pattern of disease progression on first-line erlotinib in real-life practice in patients with advanced/metastatic EGFR-mutant NSCLC.
\end{abstract}

Correspondence to: José Trigo, Servicio de Oncología Médica, Hospital Universitario Virgen de la Victoria, Campus de Teatinos, S/N, 29010, Málaga, Spain. Tel: +34 951032250, Fax: +34 951032249, e-mail: jmtrigo@ seom.org

Key Words: Epidermal growth factor receptor, EGFR, tyrosine kinase inhibitors, TKIs, erlotinib, non-small-cell lung cancer, NSCLC, progression patterns, re-biopsy.
Additionally, the presence of liver metastases may negatively affect PFS in these patients.

Non-small-cell lung cancer (NSCLC), accounting for more than $85 \%$ of lung cancer cases, is the leading cause of cancer-related death worldwide (1). Most patients with NSCLC present with locally advanced or metastatic disease at initial diagnosis (1). The standard first-line treatment has traditionally consisted of platinum-based combination chemotherapy, but unfortunately, it provides a modest overall survival (OS) benefit (2-4).

Increased knowledge of the molecular biology of lung cancer has shifted the treatment paradigm towards individualized therapy based on molecular characterization of the tumor. Accordingly, epidermal growth factor receptor (EGFR) has become an important molecular target in NSCLC, and has led to the development of tyrosine kinase inhibitors (TKIs) such as gefitinib, erlotinib, afatinib, and the third-generation TKI osimertinib. The presence of EGFRactivating mutations has been associated with a superior clinical benefit of EGFR-TKIs in patients with advanced NSCLC (5-8). Compared to standard first-line platinumbased chemotherapy, treatment with EGFR-TKIs has shown a significantly improved clinical outcome in patients harboring activating mutations in exons 18-21 which encode the tyrosine-kinase domain of the EGFR gene (5-10). EGFRTKI therapy has, therefore, emerged as the standard of care in the first-line setting for patients with NSCLC and EGFRactivating mutations. 
However, despite the striking initial response and the significant survival benefit obtained with EGFR-TKIs, most patients treated with these targeted agents eventually develop local progression or distant metastases $(11,12)$. Acquired resistance to EGFR-TKIs typically occurs in most patients within a 10 - to 14 -month period $(5-7,9,13,14)$. Acquired EGFR T790M mutation in exon 20 is responsible for resistance in up to $60 \%$ of patients treated with EGFR-TKIs (15). However, other mechanisms have been identified to account for resistance, including target gene alteration (i.e. EGFR amplification); MET proto-oncogene, receptor tyrosine kinase $(M E T)$ or human epidermal receptor 2 (HER2) amplification; B-Raf proto-oncogene, serine/ threonine kinase $(B R A F)$ or phosphatidylinositide 3-kinase $(P I 3 K)$ mutation; and phenotypic transformation (16). Updated data on tumor characteristics after development of clinical resistance should, therefore, be used for clinical decision making. Thus, re-biopsy on disease progression is now recommended as routine practice in current clinical practice guidelines, including those of the European Society for Medical Oncology (17).

Discontinuation of EGFR-TKIs and a switch to chemotherapy is a common strategy used when progressive disease (PD) occurs during treatment with EGFR-TKIs. However, due to the better tolerability of EGFR-TKIs compared with cytotoxic chemotherapy agents, continuing EGFR-TKI therapy beyond radiological PD has emerged as an adequate strategy for patients with EGFR-mutated NSCLC (14). Indeed, discontinuing treatment with EGFRTKIs after disease progression may result in accelerated tumor growth and worsening of lung cancer-related symptoms, a phenomenon known as 'disease flare' (18).

There is growing evidence to suggest that continuing EGFR-TKIs beyond disease progression might provide a survival benefit (19) even after the development of resistance, especially in patients who are asymptomatic at the time of progression (20). Indeed, second-line treatment selection for patients with EGFR-activating mutations who progress on anti-EGFR therapy depends not only on their T790M mutation status, but also on the pattern of progression, including location (single versus multiple sites) and the presence of cancer-related symptoms (asymptomatic or symptomatic) (21). However, data about progression patterns in patients with EGFR-mutant NSCLC are limited and in particular, the characterization of patterns and prognostic factors of disease progression on erlotinib in these patients is lacking.

The present study was conducted to investigate the patterns of disease progression in patients with advanced or metastatic EGFR-mutated NSCLC on first-line erlotinib and identify potential clinical and molecular characteristics that may affect progression-free survival (PFS) in these patients. Secondarily, this study also addressed the clinical outcome of first-line erlotinib treatment and the feasibility of rebiopsy after disease progression on erlotinib.

\section{Patients and Methods}

Study design and patients. The ASPET study was a multicenter, prospective, observational study conducted at 43 hospitals throughout Spain. The study was approved by the Ethics Committee of Miguel Servet Hospital (Zaragoza, Spain) (approval number: 10/2012), and written informed consent was obtained from all patients before they were included in the study. The study was carried out in accordance with the Declaration of Helsinki and applicable regulatory requirements.

Patients with histologically or cytologically confirmed advanced or metastatic (stage IIIB/IV) NSCLC with confirmed EGFRactivating mutations (mutations in the exons 18-21 of the EGFR gene) receiving erlotinib monotherapy as first-line treatment for advanced or metastatic disease according to routine clinical practice were eligible to be included in the study. Patients were excluded if they had received prior systemic chemotherapy for advanced or metastatic disease. However, the previous use of neoadjuvant or adjuvant chemotherapy was permitted as long as it had been completed more than 6 months before initiation of erlotinib treatment. Patients who had received radiotherapy within 14 days prior to starting erlotinib were also excluded.

Eligible patients were prospectively followed-up until 24 months from the inclusion of the last patient in the study or until premature withdrawal for any cause including death, whichever came first, in order to characterize their clinical management and outcome. Study visits were performed every 2 months during erlotinib treatment according to routine clinical practice. After completion or discontinuation of erlotinib, patients were followed-up every 3 months for evaluation of clinical outcome until death or study completion (24 months after the inclusion of the last patient), whichever was earlier.

Tumor response was evaluated according to local clinical practice and using version 1.1 of the Response Evaluation Criteria in Solid Tumors (RECIST) during erlotinib treatment (22). It was subsequently assessed at the follow-up visits after treatment completion (every 3 months). Patients were evaluated for toxicity during erlotinib treatment and for 30 days after the last administration of erlotinib.

Statistical analysis. The primary study endpoint was the description of disease progression patterns and the association of clinical and molecular characteristics with PFS after erlotinib treatment initiation.

Disease progression patterns were characterized on the basis of the presence of cancer-related symptoms (symptomatic or asymptomatic) and location of progression as follows: i) Local progression: defined as an increase in the size of a pre-existing tumor lesion; ii) metastatic disease: at least one new lesion; iii) general progression: defined as an increase in tumor size of two or more tumor lesions that either initially responded to or progressed on erlotinib treatment.

Secondary endpoints included the objective response rate (ORR) according to RECIST criteria, OS and 1-year survival, and the safety profile of erlotinib treatment based on the incidence of adverse events (AEs) which were graded according to the National Cancer Institute Common Toxicity Criteria (NCI-CTC) version 4.0 (23). The feasibility of performing re-biopsy of the tumor in routine 
clinical practice was also evaluated as a secondary endpoint on the basis of physician responses to a questionnaire containing five items. Patient attitudes to biopsy and potential re-biopsy were also assessed through their responses to a 5-item questionnaire.

A descriptive statistical analysis was performed on the study variables including calculation of measures of central tendency and dispersion (mean \pm standard deviation, median and interquartile range) for quantitative variables, and frequencies and valid percentages for qualitative variables.

The efficacy analyses were performed on all patients who met the selection criteria and who started erlotinib treatment within 1 month prior to study initiation. PFS was calculated as the time elapsed from erlotinib treatment initiation until disease progression or death from any cause. OS was assessed from erlotinib initiation to death. Time to progression (TTP) was defined as the period of time between the start of erlotinib treatment and the date of disease progression or death due to progression, whichever occurred first. The probabilities of PFS, TTP and OS were estimated using the Kaplan-Meier method.

The following variables were assessed as potential factors associated with PFS by bivariate COX regression analyses: age ( $\leq 65$ $v s .>65$ years), gender, baseline Eastern Cooperative Oncology Group performance status (ECOG PS) (0vs. 1 and vs. 2-3; 1 vs. 23 ), smoking habit (never smoked $v s$. current smoker and $v s$. former smoker), EGFR mutations in exon 19 and exon 21 (yes vs. no), location of metastases (lung, pleura, central nervous system, lymph nodes, bone, adrenal gland, liver, other) (yes $v s$. no). Variables with associations of $p<0.2$ were analyzed in a multivariate COX regression model with stepwise selection to determine independent prognostic factors for PFS. Hazard ratios (24) and 95\% confidence intervaIs (CIs) were calculated.

All patients who had received at least one dose of the study regimen were included in the safety analysis. Toxicities were graded according to NCI-CTCAE (version 4.0).

The statistical analysis was performed using SAS statistical analysis software version 9 (SAS Institute Inc., Cary, NC, USA).

\section{Results}

Patients. From January 2014 to June 2017, a total of 144 patients were enrolled in the study. Seventeen patients were excluded either for not fulfilling the inclusion criteria $(n=14)$, because they did not receive erlotinib $(n=1)$, or due to the fact that they had been receiving erlotinib treatment for at least 1 month prior to study initiation $(n=2)$. Therefore, a total of 127 patients were evaluable for efficacy and 143 patients for safety analyses.

The demographic and clinical characteristics of the evaluable patients are shown in Table I. Briefly, approximately half of the patients were over 65 years of age, $97 \%$ were Caucasian, $65 \%$ were female, and about $65 \%$ had never smoked. The most common histological type was adenocarcinoma (93\%). ECOG PS was 0 or 1 in $71 \%$ of patients at study initiation. Most patients (95.3\%) had stage IV disease at diagnosis, involving three or more metastatic sites in about half of patients (48\%). Metastases were mainly located in the lungs $(72.4 \%)$ and were treated with radiotherapy in $28(22.1 \%)$ patients.
Table I. Patient demographics and clinical characteristics $(n=127)$.

\begin{tabular}{|c|c|}
\hline Characteristic & Value \\
\hline \multicolumn{2}{|l|}{ Age, years } \\
\hline Median (range) & $65.6(63.7-67.6)$ \\
\hline \multicolumn{2}{|l|}{ Age distribution, $\mathrm{n}(\%)$} \\
\hline$\leq 65$ Years & $59(46.5)$ \\
\hline$>65$ Years & $68(53.5)$ \\
\hline \multicolumn{2}{|l|}{ Gender, n $(\%)$} \\
\hline Male & $44(34.7)$ \\
\hline Female & $83(65.3)$ \\
\hline \multicolumn{2}{|l|}{ Race, n (\%) } \\
\hline Caucasian & $123(96.8)$ \\
\hline Asian & $3(2.4)$ \\
\hline Missing data & $1(0,8)$ \\
\hline \multicolumn{2}{|l|}{ Smoking history, $\mathrm{n}(\%)$} \\
\hline Former smoker & $31(24.4)$ \\
\hline Current smoker & $9(7.1)$ \\
\hline Never smoked & $82(64.6)$ \\
\hline Missing data & $5(3.9)$ \\
\hline \multicolumn{2}{|l|}{ ECOG PS, n $(\%)^{*}$} \\
\hline 0 & $34(26.8)$ \\
\hline 1 & $56(44.1)$ \\
\hline 2 & $26(20.5)$ \\
\hline 3 & $5(3.9)$ \\
\hline Missing data & $6(4.7)$ \\
\hline \multicolumn{2}{|l|}{ Weight loss, n (\%) } \\
\hline Overall & $24(18.9)^{\mathrm{a}}$ \\
\hline$<10 \%$ & $13(54.2)$ \\
\hline$>10 \%$ & $10(41.7)$ \\
\hline Missing specific data & $1(4.1)$ \\
\hline \multicolumn{2}{|l|}{ Tumor histology, n (\%) } \\
\hline Adenocarcinoma & $118(92.9)$ \\
\hline Squamous cell carcinoma & $2(1.6)$ \\
\hline Large cell carcinoma & $3(2.4)$ \\
\hline Carcinoma NOS & $3(2.4)$ \\
\hline Missing data & $1(0.7)$ \\
\hline \multicolumn{2}{|c|}{ Clinical stage at diagnosis, $\mathrm{n}(\%)$} \\
\hline IIIB & $6(4.7)$ \\
\hline IV & $121(95.3)$ \\
\hline \multicolumn{2}{|l|}{ Metastatic sites, n (\%) } \\
\hline 1 & $34(26.8)$ \\
\hline 2 & $32(25.2)$ \\
\hline 3 & $35(27.6)$ \\
\hline$>3$ & $26(20.4)$ \\
\hline \multicolumn{2}{|c|}{ Location of metastases, $\mathrm{n}(\%)^{\mathrm{b}}$} \\
\hline Lung & $92(72.4)$ \\
\hline Bone & $55(43.3)$ \\
\hline Lymph nodes & $53(41.7)$ \\
\hline Pleura & $35(27.6)$ \\
\hline CNS & $26(20.5)$ \\
\hline Liver & $22(17.3)$ \\
\hline \multicolumn{2}{|l|}{ Treatment of primary tumor ${ }^{\mathrm{c}}$} \\
\hline Surgery & $8(34.78)$ \\
\hline Chemotherapyd & $5(21.7)$ \\
\hline Radiotherapy & $2(8.7)$ \\
\hline
\end{tabular}

CNS: Central nervous system; ECOG PS: Eastern Cooperative Oncology Group performance status; NOS: not otherwise specified. *At diagnosis of advanced disease. ${ }^{\text {aData missing for }} 40(31.5 \%)$ patients. b Metastases present in $>10 \%$ of patients. ${ }^{c}$ Calculated for the 23 patients with data regarding primary tumor; ${ }^{\mathrm{d} O n e}$ patient received neoadjuvant chemotherapy, while four patients were treated with chemotherapy in the adjuvant setting. 


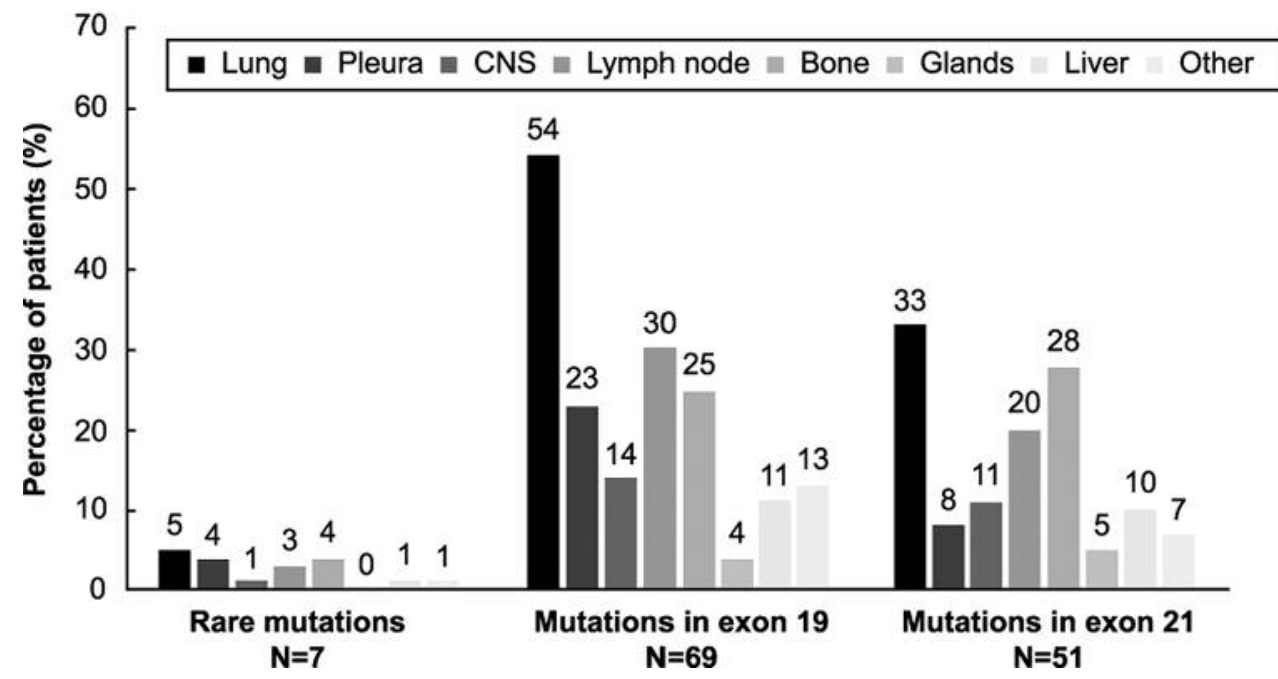

Figure 1. Location of metastases according to the type of epidermal growth factor receptor (EGFR)-activating mutation (mutations in exons 19 and 21, and rare mutations). CNS: Central nervous system.

Regarding EGFR mutational status, 69 (54.3\%) patients had exon 19 deletions and $51(40.2 \%)$ had exon 21 L858R point mutation. Rare mutations, defined as those present in exons 18 and 20 were found in seven (5.5\%) patients. EGFR mutations in exons 19 and 21 were more frequently found in those patients with metastases located in the lungs, lymph nodes, and bone (>20\% of patients) (Figure 1).

Study treatment. Dose adjustment of erlotinib was required in $38(29.9 \%)$ patients. Out of all dose adjustments performed $(\mathrm{n}=54), 11(8.6 \%)$ were due to skin toxicity while three $(2.4 \%)$ dose reductions were caused by transaminase elevation. Temporary interruption of erlotinib treatment was needed in $43(33.9 \%)$ patients. The most common reasons for erlotinib interruptions were skin toxicity $(n=18 ; 20 \%)$, diarrhea $(n=6 ; 4.6 \%)$, and transaminase elevation $(n=3$; $1.5 \%)$. Erlotinib treatment was interrupted due to erlotinibrelated adverse events (AEs) in $12(8.4 \%)$ patients. The median relative dose intensity for erlotinib (ratio of doses received to doses planned) was 1.0 (range $=0.8-1.0$ ).

The median duration of first-line treatment with erlotinib was 8.5 (range $=4.1-15.9)$ months. The most common reasons for premature erlotinib discontinuation were disease progression in $76(59.8 \%)$ patients, AEs in $15(11.8 \%)$ patients, and death in $15(11.8 \%)$. Discontinuation of erlotinib was due to investigator decision in five (3.9\%) patients and patient's decision in three (2.4\%). Erlotinib was discontinued due to losses to follow-up in two (1.6\%) patients and because of other unspecified reasons in three $(2.4 \%)$ patients. Seven (5.5\%) patients completed the planned duration of erlotinib treatment according to routine clinical practice.
Efficacy. The ORR was $53.8 \%$ and the disease control rate was $83 \%$. Of 119 evaluable patients, three (2.5\%) showed a complete response and stable disease was reported in 35 $(29.4 \%)$. The best confirmed response was partial response in $51.3 \%$ of patients $(n=61)$.

The median duration of follow-up from study treatment initiation was 15.7 (range=7.8-27.2) months. The median PFS was 8.7 (95\% $\mathrm{CI}=8.0-10.9)$ months (Figure $2 \mathrm{~A}$ ) and the median time to progression was 9.8 (95\% $\mathrm{CI}=8.4-11.9)$ months (Figure 2B). The median OS was 19.1 (95\% CI=14.720.8) months (Figure 2C). At the time of the analysis, 65 (76.5\%) patients had died due to disease progression.

Disease flare was only observed in three $(2.54 \%)$ patients after discontinuing erlotinib treatment.

Safety. Overall, $136(95.1 \%)$ patients suffered from AEs related to erlotinib. Fewer than one quarter of patients $(n=34$; $23.8 \%$ ) experienced at least one grade 3 toxicity, with skin toxicity $(10.5 \%)$ and diarrhea $(4.2 \%)$ being the most common toxicities reported (in more than two patients). Grade 4 toxicities were detected in only three patients (skin toxicity, gastrointestinal toxicity, and decreased lymphocyte count in one patient each). Erlotinib-related AEs are summarized in Table II.

Nine serious AEs considered to be related to erlotinib were reported in $7(5 \%)$ patients. The most frequent serious $\mathrm{AE}$ was grade 3 diarrhea in four patients. Grade 3 skin toxicity, asthenia, acute renal failure, and enteritis were reported in one patient each. Only one patient experienced a grade 4 serious AE (decreased lymphocyte count). None of the patients died due to a serious AEs related to erlotinib. 

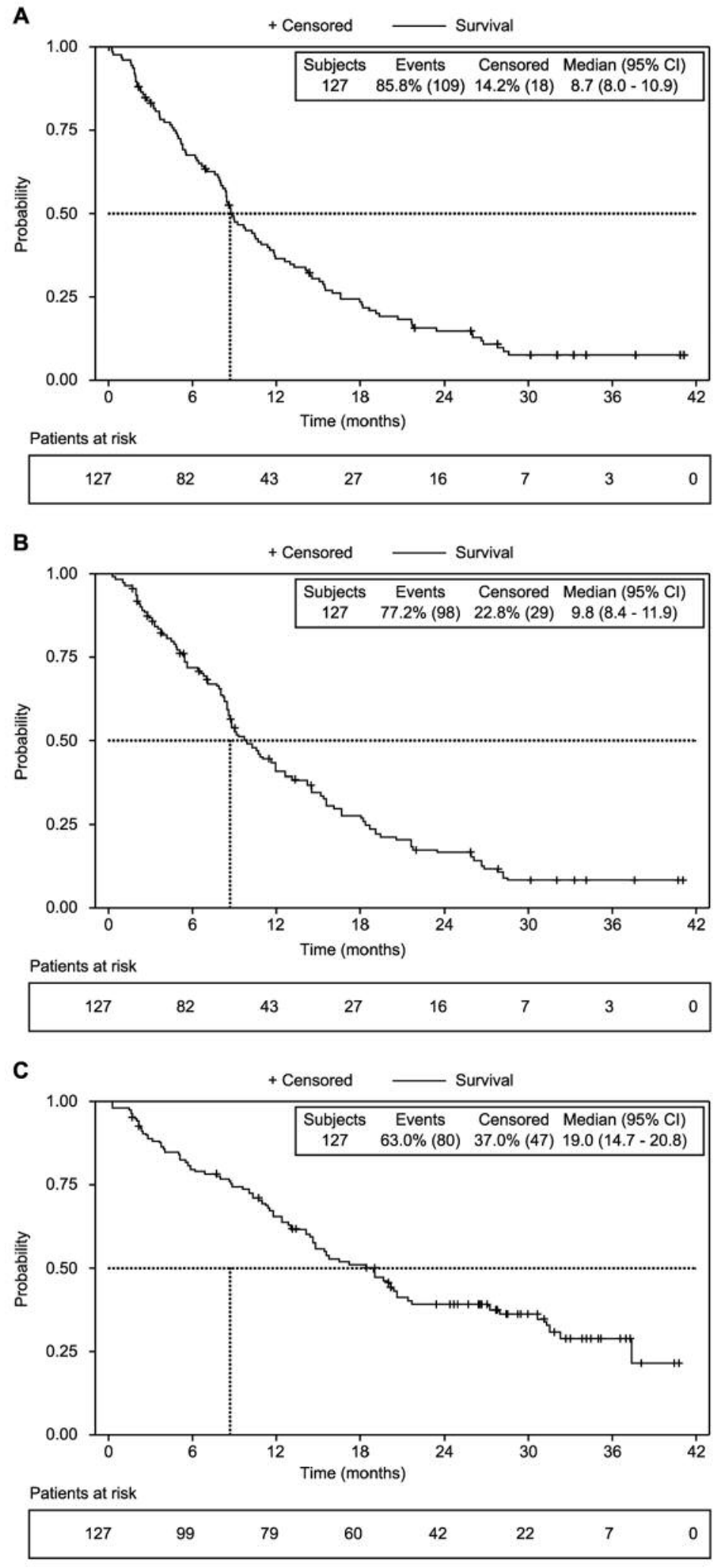

Figure 2. Kaplan-Meier curves for progression-free survival (A), time to progression (B), and overall survival (C). Patients were censored at the date of last available follow-up if still alive or without disease progression at the time of the analysis. When analyzing progression-free survival, those patients receiving a second-line treatment without disease progression on first-line erlotinib treatment were censored. CI: Confidence interval. 
Table II. Erlotinib-related adverse events (n=143) according to National Cancer Institute Common Terminology Criteria for Adverse Events (23).

\begin{tabular}{|c|c|c|c|c|c|c|c|c|}
\hline \multirow[t]{2}{*}{ Toxicity } & \multicolumn{2}{|c|}{ Grade $1^{\mathrm{a}}$} & \multicolumn{2}{|c|}{ Grade $2^{\mathrm{a}}$} & \multicolumn{2}{|c|}{ Grade $3^{\mathrm{a}}$} & \multicolumn{2}{|c|}{ Grade $4^{\mathrm{b}}$} \\
\hline & $\mathrm{N}$ & $\%$ & $\mathrm{~N}$ & $\%$ & $\mathrm{~N}$ & $\%$ & $\mathrm{~N}$ & $\%$ \\
\hline Diarrhea & 47 & 32.9 & 28 & 19.6 & 6 & 4.2 & -- & -- \\
\hline Skin toxicity & 50 & 35.0 & 50 & 35.0 & 15 & 10.5 & 1 & 0.7 \\
\hline Asthenia & 18 & 12.6 & 10 & 7.0 & 2 & 1.4 & -- & -- \\
\hline Mucosal inflammation & 12 & 8.4 & 7 & 4.9 & 1 & 0.7 & -- & -- \\
\hline Pruritus & 14 & 9.8 & 4 & 2.8 & 1 & 0.7 & -- & -- \\
\hline Paronychia & 12 & 8.4 & 7 & 4.9 & 1 & 0.7 & -- & -- \\
\hline Decreased appetite & 12 & 8.4 & 5 & 3.5 & 0 & 0.0 & -- & -- \\
\hline Dry skin & 13 & 9.1 & 4 & 2.8 & 0 & 0.0 & -- & -- \\
\hline Conjunctivitis & 11 & 7.7 & 2 & 1.4 & 0 & 0.0 & -- & -- \\
\hline Abdominal pain & 6 & 4.2 & 5 & 3.5 & 0 & 0.0 & -- & -- \\
\hline Acne & 6 & 4.2 & 4 & 2.8 & 0 & 0.0 & -- & -- \\
\hline Erythema & 8 & 5.6 & 2 & 1.4 & 0 & 0.0 & -- & -- \\
\hline Nausea & 7 & 4.9 & 2 & 1.4 & 0 & 0.0 & -- & -- \\
\hline Folliculitis & 3 & 2.1 & 4 & 2.8 & 1 & 0.7 & -- & -- \\
\hline Alopecia & 6 & 4.2 & 1 & 0.7 & 0 & 0.0 & -- & -- \\
\hline Nail toxicity & 6 & 4.2 & 1 & 0.7 & 0 & 0.0 & -- & -- \\
\hline Skin fissures & 5 & 3.5 & 1 & 0.7 & 0 & 0.0 & -- & -- \\
\hline Stomatitis & 5 & 3.5 & 1 & 0.7 & 0 & 0.0 & -- & -- \\
\hline Decreased lymphocyte count & -- & -- & -- & -- & -- & -- & 1 & 0.7 \\
\hline Gastrointestinal toxicity & -- & -- & -- & -- & -- & -- & 1 & 0.7 \\
\hline
\end{tabular}

In order to assess toxicity per patient, the maximum grade for each adverse event recorded during the study was considered for evaluation. aThe most common adverse events detected in more than $3 \%$ of patients ( $>5$ patients) each. b All grade 4 toxicities experienced by the patients are shown.

Patterns of disease progression. Disease progression occurred during erlotinib treatment in $82(89.2 \%)$ patients. Three $(3.3 \%)$ patients experienced disease progression during the follow-up period after discontinuing erlotinib treatment and before any subsequent systemic treatment was administered. Six $(6.5 \%)$ patients had disease progression on second-line therapy initiated for reasons other than disease progression to first-line erlotinib treatment.

Disease progression was asymptomatic in 53 (57.6\%) patients. In about half of the patients, disease progression was defined by the presence of at least one new metastatic lesion $(n=49,53.3 \%)$, while local progression was found in $15(16.3 \%)$ patients. Local progression along with metastatic progression was reported in $27(29.4 \%)$ patients.

Demographic and clinical factors associated with PFS. Among the sociodemographic and clinical variables, the presence of liver metastasis $(p<0.001)$ was the only one significantly associated with PFS in the univariate analysis (Table III). Gender, age, ECOG PS, exon 19 deletion mutation, and the presence of metastases in lymph nodes and bone were also retained in the multivariate model $(p<0.2)$. The multivariate analysis only identified the presence of liver metastasis (hazard ratio=2.043; 95\% CI=1.251-3.336; $p=0.004)$ as an independent prognostic factor for PFS.
Patients with liver metastasis were more likely to have a shorter PFS.

Re-biopsy. A total of $35(27.6 \%)$ patients underwent rebiopsy. Among those patients in whom biopsy was not repeated $(n=83)$, investigator decision $(n=35,42.2 \%)$ was the most frequent reason for not performing re-biopsy, followed by patient's decision $(n=5,6 \%)$ and inaccessibility $(n=5$; $6 \%)$. Other non-specified reasons were reported in 38 $(45.8 \%)$ patients.

Investigator attitudes to re-biopsy. Among the participating investigators $(n=115)$, approximately $70 \%$ stated they would repeat biopsy for re-evaluation of mutational status at the time of disease progression. When physicians were asked about the second-line treatment-of-choice at the time of disease progression on EGFR-TKI therapy (questionnaire item 2), nearly half of the investigators (45.2\%) would maintain erlotinib and would try to perform a re-biopsy to assess the mutational status. Discontinuation of erlotinib treatment and initiation of chemotherapy was stated as the strategy that would be adopted by nearly $34.8 \%$ of investigators. Overall, $11.3 \%$ of physicians said they would choose to add empiric chemotherapy to EGFR-TKI treatment after disease progression. Most investigators (80\%) believed 
that re-biopsy would be technically feasible in terms of tumor tissue availability and sampling procedure (Table IV).

Patient attitudes to the first biopsy and potential re-biopsy. A total of 104 (82\%) patients answered the questionnaire. Most patients considered that biopsy was bothersome or painful (63.5\%). However, only seven (6.7\%) patients stated they would refuse a repeat biopsy in the future (Table V).

Therapy after disease progression. Nearly $60 \%$ of patients $(\mathrm{n}=74)$ received EGFR-TKI therapy after disease progression. A total of $47(37 \%)$ patients continued on erlotinib treatment. Thirteen (10\%) patients received gefitinib and seven (5.5\%) patients were treated with afatinib as second-line treatment Osimertinib was used in seven $(5.5 \%)$ patients. Overall, $30 \%$ of patients $(n=37)$ received cisplatin or carboplatin-based chemotherapy after disease progression. Pemetrexed and platinum combination treatment was administered to $8 \%$ of patients $(\mathrm{n}=10)$. Radiotherapy was administered to $28(22 \%)$ patients.

\section{Discussion}

The present study demonstrated that metastatic progression with the development of new sites of metastasis and asymptomatic disease are the predominant patterns of disease progression on first-line erlotinib in real-life practice in patients with advanced or metastatic NSCLC carrying EGFR-activating mutations. Our findings also highlight the feasibility of repeat biopsy on disease progression in order to determine the most appropriate subsequent treatment. In addition, our data suggest that the presence of liver metastasis seems to be an independent prognostic factor for PFS in these patients. This analysis also supports the benefit of first-line erlotinib in patients with advanced or metastatic EGFR-mutated NSCLC in a real-life setting.

Efficacy data obtained in the present study show that erlotinib is an active treatment in terms of tumor response and survival in patients with advanced EGFR mutationpositive NSCLC. As a descriptive comparison only, our efficacy results are in keeping with those previously reported in the EUTARC trial with erlotinib first-line treatment in European patients with EGFR mutation-positive NSCLC (7). Thus, the median PFS achieved in this study with erlotinib (8.8 months), although slightly shorter, was consistent with that described in the EUTARC trial with this targeted agent (9.7 months), wherein PFS with erlotinib was significantly longer than that observed with chemotherapy (5.2 months) (7). In addition, the median OS achieved with erlotinib in our series (19.1 months) was in line with the survival data described in the abovementioned trial with erlotinib (19.3 months), wherein no significant OS advantage was demonstrated compared with chemotherapy, probably due to
Table III. Univariate analysis of demographic and clinical characteristics associated with progression-free survival in patients treated with first-line erlotinib therapy.

\begin{tabular}{|c|c|c|}
\hline \multirow[b]{2}{*}{ Endpoint } & \multicolumn{2}{|c|}{ Univariate analysis } \\
\hline & HR $(95 \% \mathrm{CI})$ & $p$-Value \\
\hline \multicolumn{3}{|l|}{ Age } \\
\hline$\leq 65 v s .>65$ years & $0.772(0.527-1.129)$ & 0.182 \\
\hline \multicolumn{3}{|l|}{ Gender } \\
\hline Male $v s$. female & $1.398(0.947-2.065)$ & 0.092 \\
\hline \multicolumn{3}{|l|}{ ECOG PS } \\
\hline 0 vs. 2-3 & $0.584(0.345-0.987)$ & 0.101 \\
\hline 1 vs. 2-3 & $0.665(0.418-1.057)$ & --- \\
\hline \multicolumn{3}{|l|}{ Smoking habit } \\
\hline Active smoker $v s$. never smoked & $1.036(0.498-2.155)$ & 0.899 \\
\hline Former smoker vs. never smoked & $1.110(0.712-1.731)$ & --- \\
\hline \multicolumn{3}{|l|}{ Mutation } \\
\hline Exon 19 & $1.301(0.892-1.896)$ & 0.172 \\
\hline Exon 21 & $0.914(0.622-1.341)$ & 0.644 \\
\hline \multicolumn{3}{|l|}{$\begin{array}{l}\text { Location of metastases } \\
\text { (yes } v s . \text { no) }\end{array}$} \\
\hline Lung & $0.818(0.536-1.248)$ & 0.350 \\
\hline Pleura & $1.182(0.783-1.783)$ & 0.426 \\
\hline CNS & $0.966(0.598-1.561)$ & 0.887 \\
\hline Lymph nodes & $1.441(0.985-2.108)$ & 0.059 \\
\hline Bone & $1.453(0.994-2.125)$ & 0.054 \\
\hline Adrenal gland & $1.160(0.564-2.386)$ & 0.688 \\
\hline Liver & $1.716(1.068-2.757)$ & 0.025 \\
\hline Other & $0.960(0.585-1.575)$ & 0.871 \\
\hline
\end{tabular}

CI: Confidence intervaI; CNS: central nervous system; ECOG PS: Eastern Cooperative Group performance status HR: hazard ratio.

the high crossover rate from chemotherapy to an EGFR-TKI, confounding the detection of any OS advantage. It is noteworthy that nearly $30 \%$ of patients were alive 36 months after erlotinib treatment initiation in our series. Additionally, the ORR of 54\% was also comparable to that shown in the EUTARC trial with erlotinib (58\%). Of note, despite the inclusion of approximately $6 \%$ of patients with mutations in exon 20 which are less sensitive to EGFR-TKIs (25), the clinical outcome data from this study are comparable to those reported in the EUTARC trial in which only patients with sensitizing mutations were included.

Our findings suggest that erlotinib, administered as firstline treatment, is well tolerated in patients with advanced or metastatic NSCLC. Toxicity related to erlotinib was generally mild and manageable, and no treatment-related deaths were reported. Fewer than one quarter of patients experienced grade 3 toxicities and only three patients suffered from grade 4 toxicities. Safety findings are in line with phase III trials with erlotinib, with no new or unexpected safety signals observed $(7,8)$. In keeping with randomized trials using erlotinib, the most common grade 3 AEs were skin rash and diarrhea. Although erlotinib was 
Table IV. Results from physician questionnaire concerning re-biopsy ( $n=115)$.

\begin{tabular}{lcc}
\hline & & Response, N (\%) \\
\cline { 2 - 3 } Questionnaire items $^{\mathrm{a}}$ & Yes & No \\
\hline $\begin{array}{l}\text { Item 1. In the case of disease progression, would you be willing to repeat } \\
\text { biopsy to re-evaluate the mutational status? }\end{array}$ & $83(72.2)$ & $8(6.7)$ \\
$\begin{array}{l}\text { Item 3. Depending on the results of re-biopsy, would you change your } \\
\text { decision about the treatment to be used in the second line? }\end{array}$ & $81(70.4)$ & $3(2.6)$ \\
$\begin{array}{l}\text { Item 4. Do you think that re-biopsy would be feasible in terms of } \\
\text { tumor availability and sampling procedure? }\end{array}$ & $92(80.0)$ & $3(2.6)$ \\
Item 5. Do you think the patient would be willing to repeat the biopsy? & $29(25.2)$ & $83(82.2)$ \\
\hline
\end{tabular}

aThe results of the questionnaire items 1, 3, 4 and 5 are displayed.

Table V. Results from patient questionnaires regarding their attitude to biopsy and potential re-biopsy ( $n=104)$.

\begin{tabular}{|c|c|c|c|c|}
\hline \multirow[b]{2}{*}{ Questionnaire items } & \multicolumn{4}{|c|}{ Response, $\mathrm{N}(\%)$} \\
\hline & Not uncomfortable & Uncomfortable & Painful & Unbearable \\
\hline Before the biopsy, you thought that it would be... & $26(25.0)$ & $44(42.3)$ & $29(27.9)$ & $5(4.8)$ \\
\hline The puncture was... & $41(39.4)$ & $43(41.35)$ & $16(15.4)$ & $4(3.8)$ \\
\hline Overall you consider the technique... & $34(32.7)$ & $49(47.1)$ & $17(16.4)$ & $4(3.8)$ \\
\hline \multirow[t]{2}{*}{ If you had undergone a previous biopsy, this has been... } & $7(6.7)$ & $45(43.3)$ & $13(12.5)$ & $39(37.5)$ \\
\hline & $\begin{array}{l}\text { I would do } \\
\text { it again }\end{array}$ & $\begin{array}{l}\text { I would } \\
\text { refuse }\end{array}$ & $\begin{array}{l}\text { I would need } \\
\text { anesthesia }\end{array}$ & $\begin{array}{l}\text { Missing } \\
\text { response }\end{array}$ \\
\hline If you needed a new biopsy in the future... & $83(79.8)$ & $7(6.7)$ & $14(13.5)$ & -- \\
\hline
\end{tabular}

temporarily interrupted in about $30 \%$ of patients, this was caused by erlotinib-related toxicity in fewer than $9 \%$ of patients. The high relative dose intensity for erlotinib treatment supports the tolerance of this regimen in a real clinical setting.

In line with previous evidence, the liver seems to be a less common site of metastasis than the brain and bone in patients with NSCLC harboring EGFR mutations (26). Our results suggest that the presence of liver metastasis is independently correlated with PFS, with a higher risk of shorter PFS in patients with liver metastases treated with erlotinib in the first-line setting. These findings are therefore in line with a previous report demonstrating a worse prognosis associated with liver metastasis (27), although the study was limited by a small number of patients with NSCLC with metastasis in the liver. Hepatic metastasis has also been shown to predict poor response to erlotinib as second- and third -line treatment in patients with stage IV lung adenocarcinoma (28). The worse prognosis associated with the presence of liver metastasis is probably explained due to more aggressive disease with liver metastasis usually being associated with additional distant metastases and a higher number of metastatic sites which typically predicts worse survival (29). Our findings suggest that management of liver metastases should therefore be a priority in patients with advanced EGFR-mutation-positive NSCLC for early detection of disease progression.

However, other factors which have been associated with prognosis in advanced NSCLC such as age, ECOG PS, and EGFR mutation status were not identified as factors predicting PFS in our study $(29,30)$. The lack of difference in PFS by age and performance status may suggest that both older patients ( $>65$ years) and those with a poorer ECOG PS (2-3) may benefit from erlotinib treatment in the first-line setting. Additionally, in contrast with previous reports which have shown that a Del19 mutation is generally predictive of better efficacy than an L858R mutation (31), we found that the PFS benefit did not seem to differ between patients carrying exon 19 mutations and exon 21 mutations.

The predominant pattern of first progression on erlotinib was metastatic progression with development of new sites of metastases in half of patients followed by local progression along with metastatic progression in $30 \%$ of patients. Overall, fewer than $20 \%$ of patients had local progression 
alone. Our results therefore suggest that erlotinib might be more effective in preventing local progression than in avoiding the development of new metastases as has previously been reported with EGFR-TKIs in a retrospective study in Asian patients (32). Additionally, nearly $60 \%$ of patients progressed asymptomatically, in whom continuing EGFR-TKI therapy is recommended (20). Indeed, $60 \%$ of patients received an EGFR-TKI in the second-line setting, with $40 \%$ of patients continuing erlotinib treatment after disease progression.

After progression on EGFR-TKI therapy, a molecular analysis of resistance should be performed. In this regard, the feasibility of re-biopsy of patients with NSCLC at disease progression has already been demonstrated, as well as its potential benefit in the management of NSCLC and reassessing treatment options (33). Unfortunately, re-biopsy is not routinely used in clinical practice. Accordingly, we found that fewer than $30 \%$ of patients underwent re-biopsy on disease progression. However, when participating physicians were asked about their willingness to perform rebiopsy after disease progression, most of them (70\%) answered that they would perform a repeat biopsy in order to evaluate the mutational status on disease progression. These discrepant findings may be due to local clinical practice and the fact that re-biopsy may have not been generally adopted as a part of routine clinical practice. In addition, this study began before the approval of osimertinib for patients with EGFR-mutated NSCLC whose disease progressed on EGFR-TKI therapy and who acquired resistance due to T790M. Therefore, the fact that re-biopsy to detect T790M mutation after PD was not performed at that time may explain the relatively low rate of re-biopsy on disease progression. However, the re-biopsy rate may have increased in recent years after the incorporation of osimertinib and may continue to rise in the future. In addition, it is possible that liquid biopsy was used as an alternative method to detect T790M mutation in those cases in which tissue biopsy was not feasible, and only when liquid biopsy showed a negative result for EGFR T790M mutation (34) was tissue biopsy performed for confirmation $(17,24)$. However, the fact that performance of liquid biopsy was not recorded in the study does not allow us to know whether the relatively low rate of re-biopsy is actually explained by the performance of liquid biopsy instead of rebiopsy on disease progression.

Nearly half the physicians affirmed that they would maintain EGFR-TKI therapy after disease progression, while switching to empiric chemotherapy would be the choice made by $35 \%$ of physicians according to the questionnaire findings. Accordingly, $60 \%$ of patients received an EGFRTKI in the second-line setting, with $40 \%$ of patients continuing erlotinib therapy beyond disease progression. These findings suggest a common treatment strategy used in routine clinical practice. However, the conventional practice of discontinuation of EGFR-TKI and initiation of platinumbased chemotherapy remained the preferred approach for $30 \%$ of physicians despite the evidence on the feasibility and survival advantage of continuing EGFR-TKI therapy after PD compared to switching to chemotherapy (35). These findings can be explained due to the fact that osimertinib was not approved until 2016 and because there was limited and conflicting evidence outlining the clinical benefit of continuing an EGFR-TKI treatment at initial PD $(35,36)$. Therefore, guidelines at the time recommended a switch to platinum-based chemotherapy at the time of disease progression on EGFR-TKI therapy (37). Additionally, despite the limited effectiveness demonstrated by EGFR-TKIs used in combination with a cytotoxic drug after radiological PD (36), approximately $11 \%$ of physicians stated they would add empiric chemotherapy to the EGFR-TKI therapy. Nevertheless, most investigators affirmed that they may change their decision about the treatment to be used as second-line therapy based on the results of a re-biopsy.

Disease flare after EGFR-TKI therapy discontinuation is a concern in patients with EGFR-mutant NSCLC progressing on EGFR-TKI therapy. However, in this study the appearance of disease flare was lower than that previously reported (18, 36), probably due to the continuation of erlotinib treatment in around $40 \%$ of patients, while it might also be explained by the rapid initiation of subsequent therapy.

Although re-biopsy can be challenging in routine clinical practice due to limited tissue availability and the feasibility of the procedure, most investigators believed that re-biopsy would be technically feasible in terms of tumor tissue availability and sampling procedure. In addition, the majority of physicians assumed that the patient would be willing to undergo a repeat biopsy on disease progression. Indeed, although most patients considered that the biopsy at diagnosis was bothersome or painful, fewer than $7 \%$ of patients said they would refuse a repeat biopsy in the future.

Our findings, therefore, support the idea that re-biopsying the tumor for molecular testing at the time of progression is feasible and should become a routine procedure to guide therapeutic decision-making by physicians in a real-life setting. However, although the gold standard for the detection of resistance mechanisms is tissue re-biopsy, liquid biopsy is a useful and feasible technique when re-biopsy cannot be performed (34).

The main limitation of this study mainly arises from the limited sample population that was eventually analyzed in relation to the sample initially considered $(n=150)$. Additionally, the time period during which patients should have received erlotinib treatment was not initially defined as a part of the inclusion criteria. Therefore, patients who had been on erlotinib treatment for more than 1 month were removed from the analyses at the time of the statistical analysis for the 
assessment of the primary and secondary endpoints, with the exception of the safety evaluation. In addition, a further limitation that should be acknowledged is the lack of data regarding new sites of metastases on disease progression.

However, despite the abovementioned limitations, this study provides useful real-world data on disease progression patterns and the clinical outcomes of patients with advanced or metastatic EGFR-mutant NSCLC undergoing first-line erlotinib treatment. Indeed, to the best of our knowledge, this is the first study evaluating the feasibility of re-biopsy on disease progression according to physicians and the attitudes of real-world patients with NSCLC regarding potential rebiopsy. In addition, to our knowledge, this is the largest prospective series focused on the assessment of patterns of disease progression and factors associated with PFS with erlotinib treatment for patients with advanced NSCLC harboring EGFR mutations.

The population of patients with NSCLC included in this real-world study reflects the demographic and clinical data traditionally described as being associated with the presence of EGFR-activating mutations. Thus, most patients were females, had never smoked, and had adenocarcinoma histology as previously seen in Caucasian patients with EGFR-mutant NSCLC $(38,39)$. Additionally, most EGFRactivating mutations were exon 19 deletions (54\%) and exon 21 L858R point mutations (40\%), which is consistent with previous data in Caucasians. Our findings might, therefore, be extrapolated to the general population with EGFR mutation-positive NSCLC.

In conclusion, this study supports the use of erlotinib as an effective first-line treatment option with manageable toxicity in patients with advanced or metastatic NSCLC carrying EGFR mutation. Furthermore, metastatic progression with asymptomatic disease has been identified as the predominant pattern of disease progression. This analysis also supports the potential prognostic value of liver metastasis on PFS in this population. Additionally, the feasibility of re-biopsy on disease progression with erlotinib treatment has been emphasized.

\section{Acknowledgements}

The Authors would like to thank the ASPET Study investigators for their contribution to the study. We also thank Roche Farma S.A. for supporting the study.

The Authors would also like to thank Cristina Vidal and Antonio Torres, from Dynamic Science (Spain), for their medical writing and editorial support, funded by Roche Farma S.A.

\section{Authors' Contributions}

J. Trigo contributed to the conception and design of the study, acquisition and interpretation of data, and manuscript preparation and critical review. A.L. Ortega-Granados, A. Artal-Cortes, D. AguiarBujanda, J. Oramas, J.L. Fírvida, J. de Castro, and J. Campillo
Fuentes contributed to the acquisition of data and critical review of the manuscript. R. Gordo and R. Galán participated in the conception, design and follow-up of the study, and in the critical review of the manuscript. All Authors approved the final version of the manuscript.

\section{Conflicts of Interests}

Dr. Trigo has served on advisory boards for Takeda, BMS and Boehringer and has also received speaker fees from BMS, Boehringer, Roche and Astrazeneca. Dr. Ortega-Granados has received research funding from Roche, Boehringer Ingelheim, BristolMyers-Squibb, and MSD. She has also received personal fees and non-financial support from Roche, Boehringer Ingelheim, BristolMyers-Squibb, MSD (lectures, travelling and writing assistance). Dr. Artal-Cortes has received travel support from Roche and served on advisory boards for this company. Dr. Aguiar-Bujanda has received personal fees for giving lectures from Roche and AstraZeneca. Dr. Fírvida has participated in advisory boards for Astra Zeneca, Boehringer, Lilly, MSD, and Roche. Dr. Oramas and Dr. Campillo declare that they have no competing interests. Rocio Gordo and Raquel Galán are Roche Farma employees (Medical Department).

\section{References}

1 Jemal A, Bray F, Center MM, Ferlay J, Ward E and Forman D: Global cancer statistics. CA Cancer J Clinic 61: 69-90, 2011. PMID: 21296855. DOI: 10.3322/caac.20107.

2 Hoang T, Xu R, Schiller JH, Bonomi P and Johnson DH: Clinical model to predict survival in chemonaive patients with advanced non-small-cell lung cancer treated with thirdgeneration chemotherapy regimens based on Eastern Cooperative Oncology Group data. J Clin Oncol 23: 175-183, 2005. DOI: 10.1200/JCO.2005.04.177. PMID: 15625371.

3 Scagliotti GV, De Marinis F, Rinaldi M, Crino L, Gridelli C, Ricci S, Matano E, Boni C, Marangolo M, Failla G, Altavilla G, Adamo V, Ceribelli A, Clerici M, Di Costanzo F, Frontini L and Tonato M: Phase III randomized trial comparing three platinum-based doublets in advanced non-small-cell lung cancer. J Clin Oncol 20: 42854291, 2002. PMID: 12409326. DOI: 10.1200/JCO.2002.02.068.

4 Schiller JH, Harrington D, Belani CP, Langer C, Sandler A, Krook J, Zhu $\mathrm{J}$ and Johnson DH: Comparison of four chemotherapy regimens for advanced non-small-cell lung cancer. N Engl J Med 346: 92-98, 2002. PMID: 11784875. DOI: 10.1056/NEJMoa011954.

5 Mitsudomi T, Morita S, Yatabe Y, Negoro S, Okamoto I, Tsurutani J, Seto T, Satouchi M, Tada H, Hirashima T, Asami K, Katakami N, Takada M, Yoshioka H, Shibata K, Kudoh S, Shimizu E, Saito H, Toyooka S, Nakagawa K and Fukuoka M: Gefitinib versus cisplatin plus docetaxel in patients with nonsmall-cell lung cancer harbouring mutations of the epidermal growth factor receptor (WJTOG3405): An open label, randomised phase 3 trial. Lancet Oncol 11: 121-128, 2010. PMID: 20022809. DOI: 10.1016/S1470-2045(09)70364-X.

6 Mok TS, Wu YL, Thongprasert S, Yang CH, Chu DT, Saijo N, Sunpaweravong P, Han B, Margono B, Ichinose Y, Nishiwaki Y, Ohe Y, Yang JJ, Chewaskulyong B, Jiang H, Duffield EL, Watkins CL, Armour AA and Fukuoka M: Gefitinib or carboplatin-paclitaxel in pulmonary adenocarcinoma. New Engl J Med 361: 947-957, 2009. PMID: 19692680. DOI: 10.1056/ NEJMoa0810699. 
7 Rosell R, Carcereny E, Gervais R, Vergnenegre A, Massuti B, Felip E, Palmero R, Garcia-Gomez R, Pallares C, Sanchez JM, Porta R, Cobo M, Garrido P, Longo F, Moran T, Insa A, De Marinis F, Corre R, Bover I, Illiano A, Dansin E, de Castro J, Milella M, Reguart N, Altavilla G, Jimenez U, Provencio M, Moreno MA, Terrasa J, Munoz-Langa J, Valdivia J, Isla D, Domine M, Molinier O, Mazieres J, Baize N, Garcia-Campelo R, Robinet G, Rodriguez-Abreu D, Lopez-Vivanco G, Gebbia V, Ferrera-Delgado L, Bombaron P, Bernabe R, Bearz A, Artal A, Cortesi E, Rolfo C, Sanchez-Ronco M, Drozdowskyj A, Queralt C, de Aguirre I, Ramirez JL, Sanchez JJ, Molina MA, Taron M and Paz-Ares L: Erlotinib versus standard chemotherapy as firstline treatment for European patients with advanced EGFR mutation-positive non-small-cell lung cancer (EURTAC): A multicentre, open-label, randomised phase 3 trial. Lancet Oncol 13: 239-246, 2012. PMID: 22285168. DOI: 10.1016/S14702045(11)70393-X.

8 Zhou C, Wu YL, Chen G, Feng J, Liu XQ, Wang C, Zhang S, Wang J, Zhou S, Ren S, Lu S, Zhang L, Hu C, Luo Y, Chen L, Ye M, Huang J, Zhi X, Zhang Y, Xiu Q, Ma J and You C: Erlotinib versus chemotherapy as first-line treatment for patients with advanced EGFR mutation-positive non-small-cell lung cancer (OPTIMAL, CTONG-0802): a multicentre, open-label, randomised, phase 3 study. Lancet Oncol 12: 735-742, 2011. PMID: 21783417. DOI: 10.1016/S1470-2045(11)70184-X.

9 Maemondo M, Inoue A, Kobayashi K, Sugawara S, Oizumi S, Isobe $\mathrm{H}$, Gemma A, Harada M, Yoshizawa H, Kinoshita I, Fujita Y, Okinaga S, Hirano H, Yoshimori K, Harada T, Ogura T, Ando M, Miyazawa H, Tanaka T, Saijo Y, Hagiwara K, Morita S and Nukiwa T: Gefitinib or chemotherapy for nonsmall-cell lung cancer with mutated EGFR: New Engl J Med 362: 2380-2388, 2010. PMID: 20573926. DOI: 10.1056/NEJMoa0909530.

10 Sequist LV, Yang JC, Yamamoto N, O'Byrne K, Hirsh V, Mok T, Geater SL, Orlov S, Tsai CM, Boyer M, Su WC, Bennouna J, Kato T, Gorbunova V, Lee KH, Shah R, Massey D, Zazulina V, Shahidi M and Schuler M: Phase III study of afatinib or cisplatin plus pemetrexed in patients with metastatic lung adenocarcinoma with EGFR mutations. J Clin Oncol 31: 3327-3334, 2013. PMID: 23816960. DOI: 10.1200/JCO.2012.44.2806.

11 Engelman JA and Janne PA: Mechanisms of acquired resistance to epidermal growth factor receptor tyrosine kinase inhibitors in non-small cell lung cancer. Clin Cancer Res 14: 2895-2899, 2008. PMID: 18483355. DOI: 10.1158/1078-0432.CCR-072248 .

12 Jackman D, Pao W, Riely GJ, Engelman JA, Kris MG, Janne PA, Lynch T, Johnson BE and Miller VA: Clinical definition of acquired resistance to epidermal growth factor receptor tyrosine kinase inhibitors in non-small-cell lung cancer. J Clinical Oncol 28: 357-360, 2010. PMID: 19949011. DOI: 10.1200/JCO.2009. 24.7049. 3870288.

13 Cardona AF, Arrieta O, Zapata MI, Rojas L, Wills B, Reguart N, Karachaliou N, Carranza H, Vargas C, Otero J, Archila P, Martin C, Corrales L, Cuello M, Ortiz C, Pino LE, Rosell R and Zatarain-Barron ZL: Acquired resistance to erlotinib in EGFR Mutation-positive lung adenocarcinoma among Hispanics (CLICaP). Targeted Oncol 12: 513-523, 2017. PMID: 28620690. DOI: $10.1007 / \mathrm{s} 11523-017-0497-2$.

14 Oxnard GR, Arcila ME, Sima CS, Riely GJ, Chmielecki J, Kris MG, Pao W, Ladanyi M and Miller VA: Acquired resistance to
EGFR tyrosine kinase inhibitors in EGFR-mutant lung cancer: Distinct natural history of patients with tumors harboring the T790M mutation. Clin Cancer Res 17: 1616-1622, 2011. PMID: 3060283. DOI: 10.1158/1078-0432.CCR-10-2692.

15 Yu HA, Arcila ME, Rekhtman N, Sima CS, Zakowski MF, Pao W, Kris MG, Miller VA, Ladanyi M and Riely GJ: Analysis of tumor specimens at the time of acquired resistance to EGFR-TKI therapy in 155 patients with EGFR-mutant lung cancers. Clin Cancer Res 19: 2240-2247, 2013. PMID: 3630270. DOI: 10.1158/1078-0432.CCR-12-2246.

16 Gainor JF and Shaw AT: Emerging paradigms in the development of resistance to tyrosine kinase inhibitors in lung cancer. J Clin Oncol 31: 3987-3996, 2013. PMID: 3805932. DOI: $10.1200 / J C O .2012 .45 .2029$.

17 Planchard D, Popat S, Kerr K, Novello S, Smit EF, Faivre-Finn C, Mok TS, Reck M, Van Schil PE, Hellmann MD and Peters S: Metastatic non-small cell lung cancer: ESMO Clinical Practice Guidelines for diagnosis, treatment and follow-up. Ann Oncol 29: iv192-iv237, 2018. PMID: 30285222. DOI: 10.1093/annonc/ mdy275.

18 Chen HJ, Yan HH, Yang JJ, Chen ZH, Su J, Zhang XC and Wu YL: Disease flare after EGFR tyrosine kinase inhibitor cessation predicts poor survival in patients with non-small cell lung cancer. Pathol Oncol Res 19: 833-838, 2013. PMID: 23716023. DOI: $10.1007 / \mathrm{s} 12253-013-9651-\mathrm{z}$.

19 Nishie K, Kawaguchi T, Tamiya A, Mimori T, Takeuchi N, Matsuda Y, Omachi N, Asami K, Okishio K, Atagi S, Okuma T, Kubo A, Maruyama Y, Kudoh S and Takada M: Epidermal growth factor receptor tyrosine kinase inhibitors beyond progressive disease: a retrospective analysis for Japanese patients with activating EGFR mutations. J Thoracic Oncol 7: 1722-1727, 2012. PMID: 23716023. DOI: 10.1097/JTO.0b013e31826913f7.

20 Becker $\mathrm{K}$ and $\mathrm{Xu} \mathrm{Y}$ : Management of tyrosine kinase inhibitor resistance in lung cancer with $E G F R$ mutation. World J Clin Oncol 5: 560-567, 2014. PMID: 25302160. DOI: 10.5306/ wjco.v5.i4.560.

21 Yang JJ, Chen HJ, Yan HH, Zhang XC, Zhou Q, Su J, Wang Z, Xu CR, Huang YS, Wang BC, Yang XN, Zhong WZ, Nie Q, Liao RQ, Jiang BY, Dong S and Wu YL: Clinical modes of EGFR tyrosine kinase inhibitor failure and subsequent management in advanced non-small cell lung cancer. Lung Cancer 79: 33-39, 2013. PMID: 23079155. DOI: 10.1016/ j.lungcan.2012.09.016.

22 Eisenhauer EA, Therasse P, Bogaerts J, Schwartz LH, Sargent D, Ford R, Dancey J, Arbuck S, Gwyther S, Mooney M, Rubinstein L, Shankar L, Dodd L, Kaplan R, Lacombe D and Verweij J: New response evaluation criteria in solid tumours: revised RECIST guideline (version 1.1). Eur J Cancer 45: 228247, 2009. PMID: 19097774. DOI: 10.1016/j.ejca.2008.10.026.

23 National Cancer Institute, National Institutes of Health, U.S. Department of Health and Human Services: Common terminology criteria for adverse events: (CTCAE), version 4.0 May 28, 2009 (Revised version 4.03: June 14, 2010). Available from: Available at http://evs.nci.nih.gov/ftp1/ CTCAE/CTCAE_4.03_2010-0614_QuickReference_5x7.pdf.

24 Oxnard GR, Thress KS, Alden RS, Lawrance R, Paweletz CP, Cantarini M, Yang JC, Barrett JC and Janne PA: Association between plasma genotyping and outcomes of treatment with osimertinib (AZD9291) in advanced non-small-cell lung cancer. J Clin Oncol 34: 3375-3382, 2016. PMID: 27354477. DOI: 10.1200/JCO.2016.66.7162. 
25 Wu JY, Wu SG, Yang CH, Gow CH, Chang YL, Yu CJ, Shih JY and Yang PC: Lung cancer with epidermal growth factor receptor exon 20 mutations is associated with poor gefitinib treatment response. Clin Cancer Res 14: 4877-4882, 2008. PMID: 26911831. DOI: 10.1158/1078-0432.CCR-07-5123.

26 Niu FY, Zhou Q, Yang JJ, Zhong WZ, Chen ZH, Deng W, He YY, Chen HJ, Zeng Z, Ke EE, Zhao N, Zhang N, Sun HW, Zhang QY, Xie Z, Zhang XC and Wu YL: Distribution and prognosis of uncommon metastases from non-small cell lung cancer. BMC Cancer 16: 149, 2016. DOI: 10.1186/s12885-0162169-5.

27 Chang YP, Chen YM, Lai CH, Lin CY, Fang WF, Huang CH, Li $\mathrm{SH}$, Chen HC, Wang CC and Lin MC: The impact of de novo liver metastasis on clinical outcome in patients with advanced non-small-cell lung cancer. PLoS One 12: e0178676, 2017. PMID: 28591157. DOI: 10.1371/journal.pone.0178676.

28 He Y, Wang Y, Boyle T, Ren S, Chan D, Rivard C, Li X, Li J, Zhou C and Hirsch FR: Hepatic Metastases is associated with poor efficacy of erlotinib as $2 \mathrm{nd} / 3 \mathrm{rd}$ line therapy in patients with lung adenocarcinoma. Med Sci Monit 22: 276-283, 2016. PMID: 26811313. DOI: 10.12659/MSM.896607

29 Paralkar VR, Li T and Langer CJ: Population characteristics and prognostic factors in metastatic non-small-cell lung cancer: A Fox Chase Cancer Center retrospective. Clin Lung Cancer 9: 116-121, 2008. PMID: 18501099. DOI: 10.3816/ CLC.2008.n.018.

30 Chen YM, Lai CH, Chang HC, Chao TY, Tseng CC, Fang WF, Wang CC, Chung YH, Wang YH, Su MC, Huang KT, Chen HC and Lin MC: The impact of clinical parameters on progressionfree survival of non-small cell lung cancer patients harboring EGFR-mutations receiving first-line EGFR-tyrosine kinase inhibitors. Lung Cancer 93: 47-54, 2016. PMID: 26898614. DOI: 10.1016/j.lungcan.2016.01.001.

31 Lee CK, Wu YL, Ding PN, Lord SJ, Inoue A, Zhou C, Mitsudomi T, Rosell R, Pavlakis N, Links M, Gebski V, Gralla RJ and Yang JC: Impact of specific epidermal growth factor receptor (EGFR) mutations and clinical characteristics on outcomes after treatment With EGFR tyrosine kinase inhibitors versus chemotherapy in EGFR-mutant lung cancer: A metaanalysis. J Clin Oncol 33: 1958-1965, 2015. PMID: 25897154. DOI: $10.1200 / J C O .2014 .58 .1736$.

32 Zhuang M CZ, Li J, Dai H, Zhuang C, Yang Z and Han J: Recurrence patterns in patients with advanced non-small cell lung cancer who have received epidermal growth factor receptor tyrosine kinase inhibitors. Eur J Oncol 21: 169-173, 2016.

33 Jekunen AP: Role of rebiopsy in relapsed non-small cell lung cancer for directing oncology treatments. J Oncol 2015: 809835, 2015. PMID: 25699082. DOI: 10.1155/2015/809835.
34 Gonzalez-Larriba JL, Lazaro-Quintela M, Cobo M, Domine M, Majem M and Garcia-Campelo R: Clinical management of epidermal growth factor receptor mutation-positive non-small cell lung cancer patients after progression on previous epidermal growth factor receptor tyrosine kinase inhibitors: the necessity of repeated molecular analysis. Transl Lung Cancer Res 6: S21S34, 2017. PMID: 29299405. DOI: 10.21037/tlcr.2017.10.03. 5750154.

35 Park K, Yu CJ, Kim SW, Lin MC, Sriuranpong V, Tsai CM, Lee JS, Kang JH, Chan KC, Perez-Moreno P, Button P, Ahn MJ and Mok T: First-Line erlotinib therapy until and beyond Response Evaluation Criteria in Solid Tumors progression in Asian patients with epidermal growth factor receptor mutation-positive non-small-cell lung cancer: The ASPIRATION Study. JAMA Oncol 2: 305-312, 2016. PMID: 26720423. DOI: 10.1001/ jamaoncol.2015.4921.

36 Soria JC, Wu YL, Nakagawa K, Kim SW, Yang JJ, Ahn MJ, Wang J, Yang JC, Lu Y, Atagi S, Ponce S, Lee DH, Liu Y, Yoh K, Zhou JY, Shi X, Webster A, Jiang H and Mok TS: Gefitinib plus chemotherapy versus placebo plus chemotherapy in EGFRmutation-positive non-small-cell lung cancer after progression on first-line gefitinib (IMPRESS): a phase 3 randomised trial. Lancet Oncol 16: 990-998, 2015. PMID: 26159065. DOI: 10.1016/S1470-2045(15)00121-7.

37 D'Addario G, Fruh M, Reck M, Baumann P, Klepetko W and Felip E: Metastatic non-small-cell lung cancer: ESMO Clinical Practice Guidelines for diagnosis, treatment and follow-up. Ann Oncol 21(Suppl 5): v116-119, 2010. PMID: 20555059. DOI: 10.1093/annonc/mdq189.

38 Arriola E, Garcia Gomez R, Diz P, Majem M, Martinez Aguillo M, Valdivia J, Paredes A, Sanchez-Torres JM, Peralta Munoz S, Barneto I, Gutierrez V, Andrade Santiago JM, Aparisi F, Isla D, Ponce S, Vicente Baz D, Artal A, Amador M and Provencio M: Clinical management and outcome of patients with advanced NSCLC carrying EGFR mutations in Spain. BMC Cancer 18: 106, 2018. PMID: 29382302. DOI: 10.1186/s12885-018-4004-7.

39 Douillard JY, Ostoros G, Cobo M, Ciuleanu T, McCormack R, Webster A and Milenkova T: First-line gefitinib in Caucasian EGFR mutation-positive NSCLC patients: A phase-IV, openlabel, single-arm study. Br J Cancer 110: 55-62, 2014. PMID: 24263064. DOI: 10.1038/bjc.2013.721. 3887309 .

Received December 31, 2018

Revised January 29, 2019

Accepted February 4, 2019 